\title{
Evaluating the Level of Urban Infrastructure Economic Benefit: Case Study of Beijing, China
}

\author{
Yin Cui
}

\begin{abstract}
The economic benefit of urban public infrastructure is the positive influence on the urban economy system generated by the use of urban infrastructure. This paper decomposes urban infrastructure economic benefit into four effects which include consumption effect, investment effect, government purchase effect and external demand effect for the first time and evaluate the level of urban infrastructure economic benefit taking Beijing for example. We analyzed the level of urban infrastructure economic benefit by entropy method. The result showed that the urban infrastructure economic benefit of Beijing was at the different level in different years. The change of it was in an obvious fluctuating trend. It should be improved in the future.
\end{abstract}

Index Terms-Urban infrastructure, economic benefit, decomposed effects, entropy method.

\section{INTRODUCTION}

As the basic condition of economy development, infrastructure has significant impact on the economy system of the region [1]-[5]. It affects other industrial sectors in the economy through external effect and spillover effect [6]-[8]. The economic benefit of urban infrastructure is the positive influence on the economy system generated by the use of urban infrastructure which includes promoting consumption, attracting investment, increasing revenue, stimulating exports, and so on. Many scholars have investigated the economic impact of urban public infrastructure. However, the previous studies rarely analyzed the impact of urban public infrastructure on the economy system comprehensively. The research on the whole urban infrastructure economic benefit was overlooked before.

This paper takes Beijing as an example to analyze the economic benefit of urban public infrastructure which is the capital city of China. The investment and construction scale of urban public infrastructure in Beijing is giant and increasing quickly year by year. But the basic function of urban public infrastructure in the process of economic development has not been fully played in Beijing. In this paper, we try to decompose economy system into four parts which are consumption, investment, government purchase and external demand according to the national economic identity in macroeconomics theory. The impacts of urban public infrastructure on these four parts were named as consumption effect, investment effect, government purchase effect and external demand effect of urban public infrastructure respectively. These four decomposed effects of urban infrastructure economic benefit can affect each other

Manuscript received October 9, 2017; revised February 17, 2018.

Yin Cui is with Tianjin University, China (e-mail: cuiyin86@126.com). and constitute the urban infrastructure economic benefit. Therefore, this paper tries to study the level of urban infrastructure economic benefit and its different decomposed effect in Beijing.

The remaining part of this paper is organized as follows. Section II constructs the urban infrastructure economic benefit evaluation indicator system and introduces the empirical research methods used in this paper. The main results are revealed in Section III. Section IV summarizes the main conclusions and provides the policy implications.

\section{METHODOLOGY}

\section{A. Construction of Indicator Systems}

As important public goods, urban infrastructure has the obvious characteristic of external effect and spillover effect. It provides the basic condition to the operation and development of regional economy system and creates economic benefit through offering convenience for economic activities. Thus, the scope of urban infrastructure economic benefit in this paper refers to the impact of urban infrastructure on urban economy system.

This paper designed an indicator system which comprised 24 indicators to evaluate the urban infrastructure economic benefit of Beijing. As revealed in Table I, the indicator system comprises three levels. The first one is the dimensional level. This study decomposed urban economy system into four parts. Therefore, these indicators should comprehensively reveal the economic benefit which is brought about by urban public infrastructure and reflect the four decomposed effects of urban infrastructure economic benefit. The dimensional level is the four decomposed effects of urban infrastructure economic benefit.

The second one is the indicator level. This level should reveal the specific content of urban infrastructure economic benefit. Each indicator reflected the impact of urban infrastructure on every economic activity so that it contains two parts which are urban infrastructure and economic activity. Generally speaking, urban infrastructure contains energy infrastructure, water infrastructure, transportation infrastructure, sanitation infrastructure, post and telecommunication infrastructure, and disaster-preventing infrastructure. Some of them generate the economic benefit through the way of achieving operating profit. Therefore, energy infrastructure, water infrastructure, transportation infrastructure and post and telecommunication infrastructure are chosen in this paper. They charge for their users and receive the profit which is beneficial to promote the development of economy. Energy and water infrastructure contains gas supply pipeline, heating supply pipeline, power 
generation, water supply pipeline, and so on. Considering the realistic situation of Beijing, this paper selects water and gas supply pipeline and total power generation as the indicator of urban infrastructure. Transportation infrastructure was divided into urban internal transportation and external transportation. The urban internal transportation infrastructure mainly refers to urban bus and rail transit whose scale can be reflected by the traffic operating mileage and traffic operation vehicle. The urban external transportation contains railway, highway, river, seaport, air, and so on. Here we selected the railway operating mileage and the highway operating mileage as the indicators of urban external transportation. Firstly, these two transport modes are the major ways of external transportation. Secondly, other transport modes were not chosen in consideration of the real situation of Beijing and the availability of data. Therefore, the traffic operating mileage is the sum of the mileages of urban bus, rail transit, railway and highway. The traffic operation vehicle is the sum of operation vehicles of urban bus and rail transit. And then this paper chooses the number of post and telecommunication bureau and the number of telephone subscribers at the end of year as the level of post and telecommunication infrastructure. They stand for the scale of built post and telecommunication bureau and the usage amount of telecommunication infrastructure separately.

The indicators of four economic activities would be chosen in the following section. Firstly, the household final consumption expenditure was chosen as the indicator of consumption activity. This indicator reflected the final consumption demand of urban residents which is helpful to promote the increase of urban economy. Secondly, the level of investment activity was expressed through the gross capital formation. This indicator showed the total amount of capital which could form investment capability. Thirdly, the government purchasing power was the basis of government consumption. The excellent urban infrastructure is beneficial to raise the government revenue which could lead to the increase of the government consumption expenditure. It increased the output of the whole economy system. Finally, this paper chose the net export of goods and services as the indicator of external demand. Unlike the previous studies, foreign direct investment was not chosen to avoid repeat with the gross capital formation. Many scholars thought that external trade or export was mainly impacted by transportation infrastructure [9], [10]. Nevertheless, all of the well-conditioned urban infrastructures could raise the production capacity of the city and facilitate its connections with other region which is helpful to expand its export.

The value of each indicator should show the change degree of economy activity along with the change of urban infrastructures. As the amount of urban infrastructure changes, the level of economic activity will also undergo changes. It will reflect how significantly urban infrastructure impacts every economic activity. Consequently, according to the elastic calculation formula in economics, the calculating method of each indicator is shown by Eq. (1):

$$
\text { Effect }_{i, t}=\frac{\frac{\Delta Y_{i}}{Y_{i, 0}}}{\frac{\Delta X}{X_{0}}}=\frac{\frac{Y_{i, t}-Y_{i, 0}}{Y_{i, 0}}}{\frac{X_{t}-X_{0}}{X_{0}}}
$$

where $Y_{i, 0}$ represents the observed value of the $i$ th economic activity in initial year and $Y_{i, t}$ represents it in year $t ; \mathrm{X}_{0}$ represents the amount of urban infrastructure in initial year and $X_{t}$ represents it in year $t$; Effect ${ }_{i, t}$ is the impact of urban infrastructure on the $i$ th economic activity in year $t$. It indicates how much the change percentage of each economic activity is when the urban infrastructure changes $1 \%$. In other words, it means the impact of urban infrastructure on each economic activity.

TABLE I: AN EVALUATION INDICATOR SYSTEM FOR URBAN INFRASTRUCTURE ECONOMIC BENEFIT

\begin{tabular}{|c|c|}
\hline Level 1 & Level 2 \\
\hline $\begin{array}{l}\text { Consumption } \\
\text { effect }\left(U_{1}\right)\end{array}$ & $\begin{array}{l}\text { Consumption effect of traffic operating mileage }\left(\mathrm{U}_{11}\right) \\
\text { Consumption effect of traffic operation vehicle }\left(\mathrm{U}_{12}\right) \\
\text { Consumption effect of length of water and gas supply } \\
\text { pipeline }\left(\mathrm{U}_{13}\right)\end{array}$ \\
\hline $\begin{array}{l}\text { Investment } \\
\text { effect }\left(U_{2}\right)\end{array}$ & $\begin{array}{l}\text { Consumption effect of total power generation }\left(\mathrm{U}_{14}\right) \\
\text { Consumption effect of the number of post and } \\
\text { telecommunication bureau }\left(\mathrm{U}_{15}\right) \\
\text { Consumption effect of the number of telephone } \\
\text { subscribers at the end of year }\left(\mathrm{U}_{16}\right) \\
\text { Investment effect of traffic operating mileage }\left(\mathrm{U}_{21}\right) \\
\text { Investment effect of traffic operation vehicle }\left(\mathrm{U}_{22}\right) \\
\text { Investment effect of length of water and gas supply } \\
\text { pipeline }\left(\mathrm{U}_{23}\right) \\
\text { Investment effect of total power generation }\left(\mathrm{U}_{24}\right) \\
\text { Investment effect of the number of post and } \\
\text { telecommunication bureau }\left(\mathrm{U}_{25}\right) \\
\text { Investment effect of the number of telephone } \\
\text { subscribers at the end of year }\left(\mathrm{U}_{26}\right)\end{array}$ \\
\hline $\begin{array}{l}\text { Government } \\
\text { purchase } \\
\text { effect }\left(\mathrm{U}_{3}\right)\end{array}$ & $\begin{array}{l}\text { Government purchase effect of traffic operating } \\
\text { mileage }\left(\mathrm{U}_{31}\right) \\
\text { Government purchase effect of traffic operation vehicle } \\
\left(\mathrm{U}_{32}\right) \\
\text { Government purchase effect of length of water and gas } \\
\text { supply pipeline }\left(\mathrm{U}_{33}\right) \\
\text { Government purchase effect of total power generation } \\
\left(\mathrm{U}_{34}\right) \\
\text { Government purchase effect of the number of post and } \\
\text { telecommunication bureau }\left(\mathrm{U}_{35}\right) \\
\text { Government purchase effect of the number of telephone } \\
\text { subscribers at the end of year }\left(\mathrm{U}_{36}\right)\end{array}$ \\
\hline $\begin{array}{l}\text { External } \\
\text { demand } \\
\text { effect }\left(U_{4}\right)\end{array}$ & $\begin{array}{l}\text { External demand effect of traffic operating mileage } \\
\left(\mathrm{U}_{41}\right) \\
\text { External demand effect of traffic operation vehicle } \\
\left(\mathrm{U}_{42}\right) \\
\text { External demand effect of length of water and gas } \\
\text { supply pipeline }\left(\mathrm{U}_{43}\right) \\
\text { External demand effect of total power generation }\left(\mathrm{U}_{44}\right) \\
\text { External demand effect of the number of post and } \\
\text { telecommunication bureau }\left(\mathrm{U}_{45}\right) \\
\text { External demand effect of the number of telephone } \\
\text { subscribers at the end of year }\left(\mathrm{U}_{46}\right)\end{array}$ \\
\hline
\end{tabular}

\section{B. Calculation of Urban Infrastructure Economic Benefit Index}

The required data cover the period from 2000 to 2014 which came mainly from Beijing Statistics Yearbook 2000-2015. Here this paper takes the data of year 1999 as the base when calculating the change rate of each variable. Doing like this makes the index value of each year calculated under the same standard. It also can avoid the severe fluctuation of the indicator's value owing to the different base period data.

Before evaluating the level of urban infrastructure economic benefit, the weights of all of the indicators should be determined. This paper adopts the entropy method to calculate the weight of each indicator. Generally speaking, the 
entropy which is used in the field of economy and management refers to the information entropy and is the measure of the system's disorder state. Its mathematical implication equals to the thermodynamics entropy in physics. It is commonly believed that the value of information entropy which means the variation degree of each indicator is proportional to the equilibrium degree of the system structure. The higher the variation degree is, the greater the weight of the indicator is [11]. Therefore, the weight of each indicator is calculated according to the value of entropy. The detailed step is showed as follow.

Step1: Standardize the indicators by the standardized method. Different data has different measurement and magnitude. In order to eliminate the influence of dimension and magnitude, the raw data need to be standardized using Eqs. (2) and (3):

$$
\begin{aligned}
Y_{i j} & =\frac{X_{i j}-\min \left\{X_{j}\right\}}{\max \left\{X_{j}\right\}-\min \left\{X_{j}\right\}} \\
Y_{i j} & =\frac{\max \left\{X_{j}\right\}-X_{i j}}{\max \left\{X_{j}\right\}-\min \left\{X_{j}\right\}}
\end{aligned}
$$

where $X_{i j}$ is the observed value of the $j$ th indicator in year $i ; \max \left\{X_{j}\right\}$ is the maximum observed value; $\min \left\{X_{j}\right\}$ is the minimum observed value, $Y_{i j}$ is the normalized value.

When the increasing value of indicator raised the level of urban infrastructure economic benefit, Eq. (2) is applied. When the decreasing value of indicator raised the level of urban infrastructure economic benefit, Eq. (3) is applied. In this paper, the values of all of the indicators are calculated by Eq. (2).

Step2: Calculate the proportion of the $j$ th indicator value in year $i$.

$$
\varpi_{i j}=\frac{Y_{i j}}{\sum_{i=1}^{m} Y_{i j}}
$$

Step3: Calculate the information entropy of each indicator and the redundancy degree of the information entropy.

$$
\begin{gathered}
e_{j}=-\frac{1}{\ln m} \sum_{i=1}^{m}\left(\varpi_{i j} \times \ln \varpi_{i j}\right) \\
d_{j}=1-e_{j}
\end{gathered}
$$

where $e_{j}$ is defined as the information entropy of the $j$ th indicator, $0 \leq e_{j} \leq 1, d_{j}$ is the redundancy degree of the information entropy.

Step4: Calculate the weight.

$$
w_{j}=\frac{d_{j}}{\sum_{j=1}^{m} d_{j}}
$$

where $w_{j}$ is the weight of the $j$ th indicator.

Step5: Calculate the urban infrastructure economic benefit index.

$$
S_{\text {benefit }, i}=\sum_{j=1}^{n} w_{j} Y_{i j}
$$

where $S_{\text {benefit }, i}$ is the urban infrastructure economic benefit in year $i, S_{\text {benefit }, i} \in[0,1]$.

\section{RESULT}

The level of urban infrastructure economic benefit of Beijing was calculated by Eq. (8). As illustrated in Figure 1, the level of urban infrastructure economic benefit in Beijing was increasing before 2013. The highest urban infrastructure economic benefit value of Beijing emerged in year 2011 which was larger than 0.8 . The lowest one appeared in year 2001 which was higher than 0.1. Beyond that, Fig. 1 revealed the change trends of four decomposed effects of urban infrastructure environment benefit of Beijing from 2000 to 2014. The external demand effect showed different change trend with that of urban infrastructure economic benefit in some years. The change trends of other three effects mainly coincided with those of urban infrastructure economic benefit in Beijing. The values of external demand effect of Beijing have significant difference with them of other effects. The change of this effect was the most unstable. The values of other three effects were approximate in most years from 2000 to 2014 .

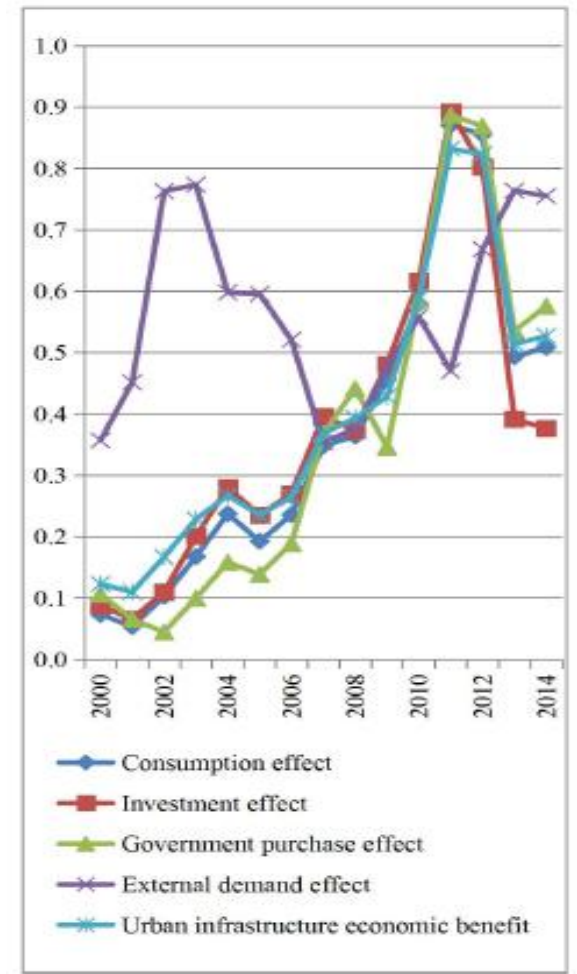

Fig. 1. Urban infrastructure economic benefit of Beijing.

The research result indicated that the urban infrastructure economic benefit of Beijing was at the different level in different years. It has dropped severely in 2013. Among these four decomposed effects, external demand effect was in an obvious fluctuating trend. The levels of other three decomposed effects were obviously lower in 2014 than them in years 2011 and 2012. It showed that the impacts of urban 
infrastructure of Beijing on the consumption and investment were relatively weaker. The whole level of urban infrastructure economic benefit was lagged owing to these three decomposed effects. It should be improved in the future.

\section{UNITS}

Use either SI (MKS) or CGS as primary units. (SI units are strongly encouraged.) English units may be used as secondary units (in parentheses). This applies to papers in data storage. For example, write " $15 \mathrm{~Gb} / \mathrm{cm}^{2}$ (100 Gb/in $\left.{ }^{2}\right)$." An exception is when English units are used as identifiers in trade, such as " $3 \frac{1}{2}$ in disk drive." Avoid combining SI and CGS units, such as current in amperes and magnetic field in oersteds. This often leads to confusion because equations do not balance dimensionally. If you must use mixed units, clearly state the units for each quantity in an equation.

The SI unit for magnetic field strength $H$ is $\mathrm{A} / \mathrm{m}$. However, if you wish to use units of $T$, either refer to magnetic flux density $B$ or magnetic field strength symbolized as $\mu_{0} H$. Use the center dot to separate compound units, e.g., "A· $\mathrm{m}^{2}$."

\section{CONCLUSIONS AND POLICY IMPLICATIONS}

According to the above empirical results, the level of urban infrastructure economic benefit of Beijing was at a lower level The levels of four decomposed effects of urban infrastructure economic benefit of Beijing were obviously different from 2000 to 2014. It has giant improvement space in the future.

In order to raise the level of urban infrastructure economic benefit, several steps should be put forward. Firstly, Beijing should highly pay attention to the correlation effect of urban infrastructure to the different economic activities and boost the basic function of urban infrastructure in the process of economy development. The effects of urban infrastructure on different economic activities should be developed simultaneously. Beijing should keep the rough balance of the development speeds of different effects. Secondly, Beijing should attach importance to the proportion among different urban infrastructures. Urban infrastructure economic benefit emerges from a variety of urban infrastructures. The inputs on them should roughly equal and fit the demand of urban development. Keeping the appropriate structure of urban infrastructure system is also an important way of raising the level of urban infrastructure economic benefit. In these ways, the development level of urban infrastructure economic benefit can be increased.

\section{REFERENCES}

[1] D. A. Aschauer, "Is public expenditure productive?" Journal of Monetary Economics, vol. 23, no. 2, pp. 177-200, 1989.

[2] C. N. Annala, R. G. Batina, and J. P. Feehan, "Empirical impact of public infrastructure on the Japanese economy,"J apanese Economic Review, vol. 59, no. 4, pp. 419-437, 2008.

[3] D. Canning and P. Pedroni, "Infrastructure, Long-run Economic Growth and Causality Tests for Co-integrated Panels," The Manchester School, vol. 76, no. 5, pp. 504-527, 2008.

[4] B. Lewis, "Urbanization and economic growth in Indonesia: good news, bad news and (possible) local government mitigation," Regional Studies, vol. 48, no. 1, pp. 192-207, 2014

[5] S. Fan and X. Zhang, "Infrastructure and regional economic development in rural China," China Economic Review, vol. 15, no. 2, pp. 203-214, 2004

[6] J. J. Laird, J. Nellthorp, and P. J. Mackie, "Network effects and total economic impact in transport appraisal," Transport Policy, vol. 12, pp. 537-544, 2005.

[7] J. P. Cohen, "The broader effects of transportation infrastructure: spatial econometrics and productivity approaches," Transportation Research Part E: Logistics \& Transportation Review, vol. 46, pp. 317-326, 2010.

[8] A. H. Munnell, "Infrastructure investment and economic growth," Journal of Economic Perspectives, vol. 6, no. 4, pp. 189-198, 1992.

[9] A. K. Cosar and B. Demir, "Domestic road infrastructure and international trade: Evidence from Turkey," Journal of Development Economics, vol. 118, pp. 232-244, 2016.

[10] C. V. Martincus, J. Carballo, and A. Cusolito, "Roads, exports and employment: Evidence from a developing country," Journal of Development Economics, vol. 125, pp. 21-39, 2017.

[11] C. R. Ai, H. J. Li, Z. J. Lin, and M. X. Meng, "Estimation of panel data partly specified Tobit regression with fixed effects," Journal of Econometrics, vol. 188, no. 2, pp. 316-326, 2015.

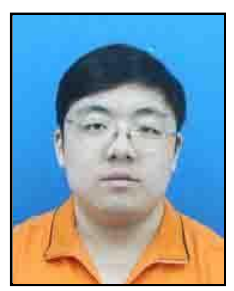

Cui Yin was born in Tianjin, China in 1986. He has achieved Master's degree of Economics in 2015. He is a Ph.D candidate of College of Management and Economics, Tianjin University. His research field is the benefit of urban public infrastructure. He has published one paper in the Journal of Mathematical Problems in Engineering. And he is interested in urban economics, public economics and development economics. 